\title{
Embodying the past, designing the future: technological determinism reconsidered in technology education
}

\author{
Jonas Hallström ${ }^{1}$ (D)
}

Accepted: 4 June 2020 / Published online: 11 June 2020

(c) The Author(s) 2020

\begin{abstract}
From a philosophical viewpoint, technological design is about connecting what is desirable with what is technically possible. Technology itself plays a major role in design processes, not only because technology development is what designing is all about, but also since the existing technology at any given point in time frames what is possible to achieve in terms of new outcomes. A limiting role of technology in design, education and other societal activities goes under the concept of technological determinism and has arguably been one of the most significant points of debate in the social sciences in the last decades. The aim of this article is to investigate how philosophical, sociological and historical research, as well as design and innovation research about technological determinism, could be fruitfully reconsidered in technology education. The analysis yielded three novel findings about the nature of technological determinism. First of all, technological determinism can take the form of an idea, theory or a way of explaining technology development in history or the present, but it can also take the form of actual material structures that-implicitly or explicitly_permeate and influence society, or, at least, this is what some researchers claim. Secondly, technological determinism is not just something that is the result of a bird's eye view of technology and society or when we study technology as part of the macro level of society. Determinism can appear on all levels, even the micro level. Thirdly, like its counterpart social/societal determinism, technological determinism is not necessarily a "bad" thing, but a natural result of design being a balance between what is societally desirable and technically possible. The most critical issue from the point of view of technological literacy is to promote the idea that it is humans that design and retain control over technology.
\end{abstract}

Keywords Technological determinism - Autonomous technology · Technology education · Technological literacy $\cdot$ Design $\cdot$ History

We forget most of our past but embody all of it.

John Updike (1995)

Jonas Hallström

jonas.hallstrom@liu.se

1 Technology and Science Education Research (TESER), Department of Behavioural Sciences and Learning, Linköping University, Norrköping, Sweden 
From a philosophical viewpoint, technological design is about connecting what is desirable with what is technically possible (Vermaas et al. 2011). Thus, whether in industrial laboratories, architectural studios or school workshops, design is influenced by a multitude of historical discourses, practices and tools, at the same time as it is by its very nature future-oriented. In a design situation problems are solved, artefacts created, and new knowledge constructed, so design is an independent, forward-looking epistemic practice (Ammon 2017), at the same time as the designing is influenced by a number of precedents, prior choices, etc. (Doboli and Umbarkar 2014). Technology itself plays a major role in design processes, not only because technology development is what designing is all about, but also since the existing technology at any given point in time- - be it in society at large, the design workshop or the classroom-frames what is possible to achieve in terms of new outcomes.

A limiting role of technology in design, education and other societal activities goes under the concept of technological determinism and has arguably been one of the most significant points of debate in the social sciences in the last decades. In his introduction to the philosophy of technology, Dusek (2006) defines technological determinism and the related concept autonomous technology as follows:

Technological determinism is the claim that technology causes or determines the structure of the rest of society and culture. Autonomous technology is the claim that technology is not in human control, that it develops with a logic of its own. The two theses are related. Autonomous technology generally presupposes technological determinism. If technology determines the rest of culture, then culture and society cannot affect the direction of technology. Technological determinism does not, on the face of it, presuppose autonomous technology. It could be that free, creative inventors devise technology, but that this technology determines the rest of society and culture (p. 84).

Feenberg (2006) expounds on the notion of autonomous technology:

To say that technology is autonomous is not of course to say that it acts alone. Human beings are involved, but the question is, do they actually have the freedom to decide how technology will be applied and develop? Is the next step in the evolution of the technical system up to human decision-makers or do they act according to a logic inscribed in the very nature of technology? In the latter case technology can rightly be said to be autonomous. On the other hand, technology would be humanly controllable if we could determine the next step in its evolution in accordance with intentions elaborated without reference to the imperatives of technology (Feenberg 2006, p. 10).

Design is concerned with the "next step" in the evolution of technology, but, surprisingly, little if anything at all has been produced in terms of research about technological determinism in technology education. The aim of this article, therefore, is to investigate how philosophical, sociological and historical research, as well as design and innovation research about technological determinism, could be fruitfully reconsidered in technology education. The study draws on a selection of literature about technological determinism in the philosophy, sociology and history of technology, technology education, design studies, innovation studies, mechanical and electronic design. Technological determinism is here viewed as an umbrella concept for a range of related concepts and problematics associated with determinism, such as autonomous technology, the neutrality thesis, momentum, and others. The arguments and implications of this study are primarily intended for 
technology education researchers, but also for technology education curriculum developers and instructors.

So far, technological determinism has mostly been addressed in the history, sociology and philosophy of technology. In the history of technology, for example, the term has often been used in reference to complex technologies and systems that, as they evolve and age, embody their history in terms of built-in components, previous choices and vested interests, thereby making these technologies determining and maybe even autonomous. Nevertheless, historians often reject "pure" technological determinism as an explanatory factor for societal development (Melosi 2000), and so do most sociologists and philosophers (e.g. Bijker 1995; Feenberg 1999). Alternative, less deterministic concepts have been proposed such as the term path dependence in social science and economic theory (Nee and Cao 1999), and the concept of momentum in the history and sociology of technology (Hughes 1983, 1987). Generally, however, there is disagreement between disciplines, and even within disciplines, about just what technological determinism means, which hinders a constructive discussion.

Pannabecker (1991) criticizes teaching about the "impact of technology" in technology education as being too deterministic when dealing with technology and society relations. De Vries (2017) also argues that the issue of technological determinism is critical in technology education because teachers and students often see artefacts as neutral instruments; they think that the technological design process follows an optimal, predetermined order, and that technological knowledge is just applied scientific knowledge (e.g. de Vries 2017, pp. 17-18, 29). These examples could all be construed as deterministic accounts of technology education (de Vries 2009; Dusek 2006; Feenberg 1999), although these authors do not go into any greater detail or relate their discussion to a wider research context on technological determinism.

\section{Defining technological determinism: a research overview}

The textbook account by Dusek constitutes a good point of departure for a discussion of how to define technological determinism. Technological determinism could, first of all, be the idea that technology determines the structure of the rest of society, much like in the above quote (Dusek 2006, p. 84). This, in turn, could be a political theory or idea employed by historical or present-day actors to achieve political or other ends. For example, engineers or politicians could have a technological system or digital algorithm designed in such a way that it becomes difficult to understand and is thereby perceived as mysterious or complex, in order to make people think that it determines their lives and that they cannot control it (Feenberg 2017; Williams 1994). Another, similarly value-laden idea of technological determinism could be found in certain scientific theories, for example modernization theory within sociology, with Weber as the most prominent proponent. The view of the potential of technology is certainly positive, but it is still deterministic in the sense that it is the application of technology that leads to a modern society (Feenberg 1999, 2006). Technological determinism as an idea could also be construed in a much more neutral sense, namely as an analytical concept or heuristic employed by researchers to be able to study and discuss the phenomenon (cf. Bimber 1990, 1994; Perdue 1994).

Secondly and conversely, technological determinism could also mean the actual, material structure shaping the course of history and societal development at any given time. The material structure could be, most obviously, various technologies and technological 
systems, but some commentators have also suggested economics as a "force field" that imposes an order on human behaviour (e.g. Heilbroner 1994). The proponents of this definition of technological determinism are mostly materialists with Karl Marx as the primary inspiration, although many philosophers and historians now also question whether Marx himself was really a technological determinist (Bimber 1994; Feenberg 2017).

Another important aspect of the material structure is what concrete technologies we are dealing with. Some technologies are more loosely structured or organized, whereas some are more opaque or systemic and thus more difficult to influence; they might then in actual fact be, or at least be perceived as, difficult to change. For instance, some nineteenth century industrial machinery was versatile and flexible, such as certain paper-making machines (Scranton 1994, pp. 164-168), while other machinery was less so. As Hughes (1987) points out, the degree of flexibility also has to do with how old and established a technology is; the more established an artefact or system, the less flexible it tends to be (Hughes 1987). One and the same technology could also have almost opposite effects on its surrounding, depending on when and how it was designed and in what context. As regards water supply and sewerage, Melosi (2000) points out:

A commitment to permanence [...] often locked in specific technologies and thus limited choices for future generations. Problems could arise if systems were either too well built or too poorly constructed. In the case of the former, an existing system could prove resistant to change; in the latter case, it might be in desperate need of replacement. As a consequence, decisions made about sanitary systems in the nineteenth century had a profound impact on cities more than 100 years later (Melosi 2000, p. 10).

Whether successful or not, infrastructure therefore stands for some kind of historical continuity, and could in this sense also be construed as determinist. For example, despite the fall of the Western Roman empire and its institutions during the early Middle Ages, there was continuity in terms of trade routes, roads and water infrastructure, which continued to be used and developed by Visigoths and later Arabs in southern Europe (e.g. Squatriti 1998). European infrastructure during the twentieth century was also arguably a means of continuity and stability in the face of recurring wars (Högselius et al. 2016; Schot and Scranton 2016).

Thirdly, does this inflexibility on the part of an established technology arise out of material properties and actual physical "inertia", or out of the perception by people that it is or should be established and hard to alter? This takes us back to the interpretation of technological determinism as idea or as structure. Here there is a wide spectrum of views, from the social constructivists who generally speak of contingency, to the materialists who mainly take the material restraints into account (Feenberg 2017). In the so-called SCOT (Social Construction of Technology) school of sociologists, one talks of the interpretative flexibility of relevant social groups as decisive for how a design turns out, so when closure is finally achieved this happens primarily when the social meaning of the design has become fixed (Bijker 1992, 1995).

One can thus talk about "stronger" or "harder" forms of determinism, as opposed to "softer" or "weaker" forms in which contingency is largely seen as prevailing, although there are restrictions imposed by technology (cf. Nightingale 2009). Kaiserfeld defines technological determinism as when technology determines institutional contexts, but outlines a continuum from stronger to weaker forms of determinism: 
In its strongest form, technological determinism is seen as a stance where technology determines institutional contexts and is itself predetermined, for example, through a strive for increased efficiency or productivity. Such notions have been underpinned by observations of simultaneous invention suggesting determining relations between established institutions and new technologies such that a specific institutional context, for instance, an accumulation of knowledge regarding a particular area, implies a definable set of inventions (Kaiserfeld 2015, p. 94).

In Kaiserfeld's view, a weaker form is when technology determines institutional structures but is not predetermined itself, which means that the social context may have influenced the evolution of technology in earlier stages. It thus seems that in situations where technology is a key factor, determinism is considered to be stronger, while the opposite is true when technology plays a minor part (Kaiserfeld 2015). Yet a weaker form of determinism, according to Kaiserfeld (2015), is when there are unintended consequences of technological development (cf. Bimber 1994; Winner 1986), for instance environmental pollution, health hazards and the like, but also beneficial side effects such as the haphazard discovery of penicillin (McClellan III and Dorn 1999).

Hughes (1987) introduces the concept of momentum, which denotes a soft determinism

Technological systems, even after prolonged growth and consolidation, do not become autonomous; they acquire momentum. They have a mass of technical and organizational components; they possess direction, or goals; and they display a rate of growth suggesting velocity. A high level of momentum often causes observers to assume that a technological system has become autonomous. Mature systems have a quality that is analogous, therefore, to inertia of motion. The large mass of a technological system arises especially from the organizations and people committed by various interests to the system. [...] Modern capital-intensive systems possess a multitude of durable physical artifacts. Laying off workers in labor-intensive systems reduces momentum, but capital-intensive systems cannot lay off capital and interest payments on machinery and processes. Durable physical artifacts project into the future the socially constructed characteristics acquired in the past when they were designed (Hughes 1987, pp. 76-77).

It is thus both durable physical artefacts and interests in a technology or system that account for the high level of momentum. However, as shown by Hallström (2011), in the case of working-class suburbs in late nineteenth century Sweden, bourgeois elites often worked various factors in favour of not extending otherwise durable sanitary systems such as water supply and sewerage, or, if one re-interprets Hughes, in diminishing their momentum. In Hughes' view, the combination of social and physical characteristics determines the evolution of the technological system, so therefore the determinism is soft; a kind of balance between contingency and determinacy. Vermaas et al. (2011) take a similar view, although they lean a little more toward the determinacy end of the spectrum, especially concerning socio-technical systems: "There is undoubtedly a kernel of truth in the [...] variants of technical determinism. [...] Technology does not develop autonomously but sociotechnical systems do, to a certain extent, develop autonomously (Vermaas et al. 2011, pp. 100-101).

If we recapitulate, the way one regards technological determinism is both related to a general outlook on the concept - an idea or theory of technological determinism and how technology relates to society in general-and how one interprets empirical data on the influence of the technological structure on the rest of society. Many of the cited researchers 
have investigated empirical (historical) data, so it may be that it boils down to what kind of data was investigated and how it was interpreted. According to Misa (1994), generally it is more common to find technologically determinist accounts of history in macro-histories, that is, in studies of the more abstracted societal level. This kind of birds-eye view makes it easier to miss the fine-grained power struggles at a local level, where individual actors' actions and experiences are studied. Micro-historical accounts, therefore, are so deeply rooted in the local context and the actors that design and negotiate new technologies, that it is virtually impossible to "find" any determinism at this level. Misa suggests a level in between, a meso level where it could be fruitful to study technological determinism (Misa 1994), although he is rather vague regarding what such a level might mean in practice. Vermaas et al. (2011) rightly point out that defining such a meso level would mean reconciling two very different perspectives, the macro and the micro, which might not be so easy.

If we apply the concepts of internalism/externalism from the history of science, an internalist perspective on technological innovation would see it as driven mainly by individual scientists and engineers and/or technical improvement, whereas an externalist perspective would consider the broader society and its social, cultural, economic and political factors and actors as the main driving forces (Shapin 1992). The internalist perspective has traditionally been seen as the more technologically determinist, and the externalist perspective the more socially oriented (or determinist), which makes sense as they focus on technological and societal factors respectively. Staudenmaier (1985) adds a third perspective - contextualist — which constitutes a recognition that the internalist and externalist perspectives need to complement one another; that is, one needs to look for the driving forces of technology in and around the artefacts and systems themselves and also in the broader societal and cultural context. The contextualist perspective could thus be said to acknowledge technological as well as non-technological actors and factors in shaping technology (Staudenmaier 1985), although Edgerton (2011) warns of underestimating the complexities of defining the context.

Mitcham (1994) is of the view that how technology comes out at different levels of analysis is a metaphysical question. At a higher level of abstraction technology may indeed seem to be uniform and unproblematic, possibly even autonomous and deterministic, whereas at a lower level of abstraction technology might rather seem diverse, "multistable" (Ihde 1990) and perhaps not at all so determining (pp. 110-112; cf. Misa's macro- and micro-historical levels). It is thus, according to Mitcham, ultimately a metaphysical question whether or not technology, in a given situation, appears to be stable and unchangeable, or changeable and possible to control. Mitcham's argument partly draws on Ihde (1990), who points to the fact that technology is multistable and diverse and can therefore never determine, although Ihde also uses the term inclination and therefore seems to acknowledge some kind of soft determinism. He argues that technology does not "'determine' [...] but it does 'incline' toward some possibilities..." (Ihde 1990, p. 142).

Related to this line of reasoning is what has been termed the "value neutrality thesis", which Ihde and several other especially critical philosophers of technology argue very strongly against (see, for example, Ellul 1962; Winner 1977). Pitt (2014) in his “Guns don’t kill; people kill" defines the value neutrality thesis as: "Technological artifacts do not have, have embedded in them, or contain values" (p. 90), and goes on to explain his pragmatist stand on this thesis (cf. Pitt 2006):

[T] echnologies themselves cannot in any legitimate sense embody values. Rather, it is people who have values. This is not to deny that specific technologies may result from individuals attempting to implement their value systems in certain ways. It is a 
result of recognizing that values are the sorts of things that inanimate objects cannot possess, embody, or have (Pitt 2014, p. 90).

Ironically, many proponents of the non-neutrality of technology and of the value neutrality thesis seem to agree upon the fact that there is a marked human element in the development of technology in society, or at least that technology development is a reflection of human, cultural and societal efforts and not intrinsic to technology itself. However, they differ in how they interpret design, choice and use of technology, which for Pitt (2014) is rather straightforward in that it is the values of humans that are imposed upon technologies, rather than the technologies having "built-in" values; since the determining factor is social, this view could be called social determinist. Winner, on the other hand, points to the proliferation of unintended consequences of especially complex technology (cf. Axell 2019), thus making the design and use of technology difficult to submit to various value systems. Winner refers to technologies as "forms of life" which alter how people think and act, and key here is the "mediating role of technical devices" (Winner 1986, p. 9), which is important to many philosophers and sociologists of technology promoting a kind of soft determinism (although they often call it something else, such as momentum or inclination):

It may seem that the view I am suggesting is that of technological determinism: the idea that technological innovation is the basic cause of changes in society and that human beings have little choice other than to sit back and watch this ineluctable process unfold. But the concept of determinism is much too strong, far too sweeping in its implications to provide an adequate theory. It does little justice to the genuine choices that arise, in both principle and practice, in the course of technical and social transformation. [...] A more revealing notion, in my view, is that of technological somnambulism. For the interesting puzzle in our times is that we so willingly sleepwalk through the process of reconstituting the conditions of human existence (Winner 1986, pp. 9-10).

Ihde (1990), following on from Winner's arguments, claims that the value neutrality of technology is really an illusion (cf. Ihde 2006):

There is a persistent illusion of neutrality that associates with all technologies. Its most simplistic form, the neutrality of mere objects in contrast to motivated uses by subjects, has been avoided here by the use of the relativistic model that refuses to dissociate subject from object, user from technology. But the illusion can persist precisely because of the multistability we have noted, in which a multiplicity of users can pick up and use technologies in such different ways (Ihde 1990, p. 164).

The critical theory developed by Feenberg similarly acknowledges the fact that technology is value-laden and he is therefore sceptical about human control over technology, although a certain degree of control can be achieved through democratic interventions (Ankiewicz 2019; Feenberg 2006, 2017).

Latour (1999), like Pitt (2014), takes the American National Rifle Association's (NRA) slogan "Guns don't kill people; people kill people" as a point of departure for his argument. However, according to Latour, neither the human gun-carrier nor the gun itself is the same when considered together, and therefore we cannot understand the mediation between the human and the gun as subject and object, but rather as a collective (this argument could thus be seen as a-perhaps slightly more extreme — variant of Ihde's post-phenomenology): "It is neither people nor guns that kill. Responsibility for action must be shared among the various actants [human and non-human actors]" (Latour 1999, p. 180). 
However, although they are few, among the critical philosophers of technology there are also determinist voices, in the sense that technology is seen as basically out of human control-technology is an autonomous force shaping society. The French philosopher Jacques Ellul's writings on the technological society can be construed as explicitly technologically determinist (e.g. Ellul 1962, 1964):

This new technical milieu has the following characteristics: a. It is artificial; b. It is autonomous with respect to values, ideas, and the state; c. It is self-determining in a closed circle. Like nature, it is a closed organization which permits it to be self-determinative independently of all human intervention; d. It grows according to a process which is causal but not directed to ends; e. It is formed by an accumulation of means which have established primacy over ends; f. All its parts are mutually implicated to such a degree that it is impossible to separate them or to settle any technical problem in isolation (Ellul 1962, pp. 394-395).

Consequently, there is basically a continuum of views of what really controls and determines societal and technology development, from the pragmatist philosophers who place them firmly in the hands of humans to the extremely critical philosophers of technology like Ellul who place them with technology and social engineering, therefore a kind of technological determinism. In between we find a number of "middle of the road" variants, supported by most analytical and critical philosophers as well as historians and sociologists. These views share the sentiment that societal and technological development, subject and object, occur in tandem in a cultural and societal context, thereby making the societal and technological outcomes multistable and largely unpredictable. There are concepts here to denote this, such as soft or weak determinism, multistability, inclination and more.

\section{Technological design and deterministic potentialities}

So what do all these conceptions of technological determinism mean for technological design processes in particular, and technology education in general? Figure 1 intends to capture the essence of technological design and how social and technical determining

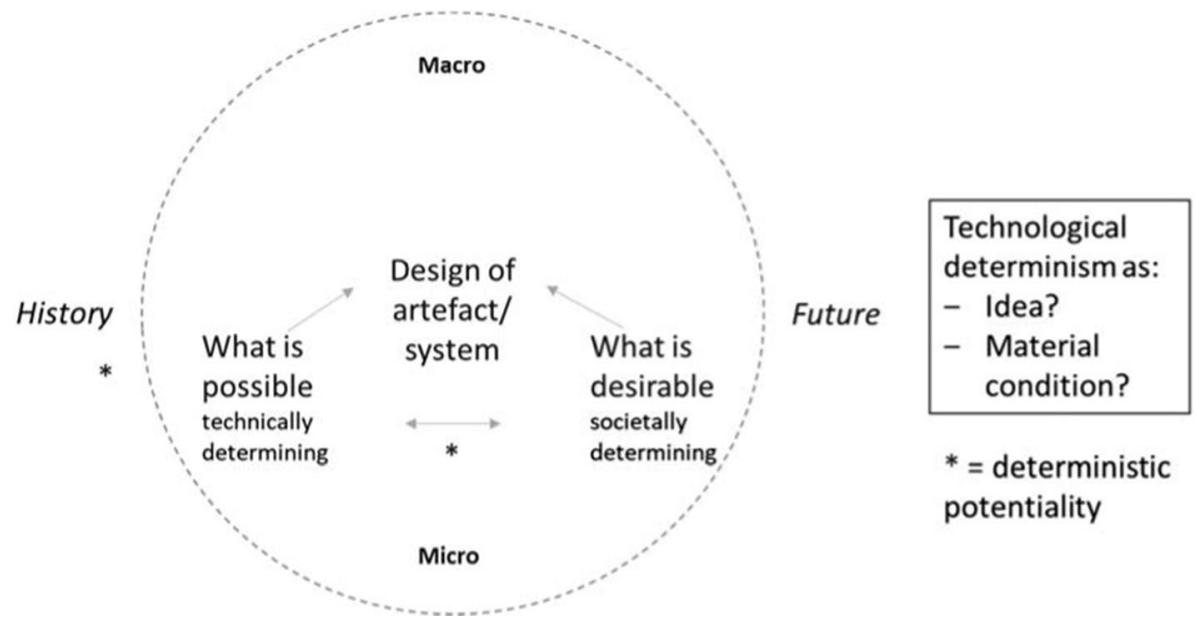

Fig. 1 Design as a societal activity-and deterministic potentialities 
factors affect design processes, at the intersection between history and the future, based on the above presentation of literature from the sociology, philosophy and history of technology. Deterministic potentialities - marked by a star-can be said to be ubiquitous in design and technological evolution, and the more general level was expounded on above in the research overview. Here I will zoom in on the two deterministic potentialities and how technological determinism might play out in design, with particular focus on implications for technology education.

Although Mitcham (1994) has a point about macro and micro in technology development - also fleshed out by Misa (1994) and Vermaas et al. (2011) in more detail-it does not really suffice to fall back on metaphysics in a concrete situation, let us say in a design workshop, or in a technology classroom. In order to be able to produce innovative design, and to teach and learn such design, design processes must be preceded by an informed analysis which takes both technological and societal determining factors into account. It is clear, for example, that the historical momentum of a technological system has some bearing on how one can develop it in the future, but the extent of the determining factors has to be sought out in each design situation. I suggest posing questions about both technological and societal determining factors when designing (see Fig. 1). The more systemic the technology that is to be designed, the greater and more complex the determining factors will be, so large socio-technical systems will be both too large and too complex to design in a school context. In fact, according to Vermaas et al. (2011), design of socio-technical systems may even be too complex for a single professional designer.

Figure 1 also suggests some deterministic potentialities. They should be interpreted as situations in which especially technological factors may determine the outcome in a way that can be construed as deterministic, but it may also be the societal factors that over-determine. Given the discussion in the previous section and the definition of design as achieving the desirable against the background of what is technically possible, one can say that they are potentialities for too much technological determinism.

Design is clearly a societal activity that is influenced by history, but also directed toward the future by being about problem-solving, creativity and innovation (Feenberg 2017). There are, however, two deterministic potentialities that need to be considered in technology education. First of all, the history of technology and the current state of the art in technology clearly set limits for what can be achieved in design; state-of-the-art technology is, in a way, embodied society, or, with Latour, "technology is society made durable" (Latour 1990). The first potentiality for technological determinism is thus the historical technological heritage coming into a design situation, and new design and innovation must stretch beyond this. Talking about a potentiality for determinism in no way implies that technological determinism is necessarily a "bad" thing-innovation often is dependent on a steady set of old technologies already in place (e.g. Edgerton 2011) - it simply means that societal influences overall need to balance the technological ones for the design to be successful. Particularly large sociotechnical systems are difficult to change, to a great extent due do their history and to them acquiring momentum when becoming established (Hughes 1987), but also their societal and technological complexity as "hybrid systems" (Kroes et al. 2006). So the greater the complexity and hybrid character of a technology, the greater the deterministic force or momentum on further design; and, thus, the greater the deterministic potentiality.

Secondly, when we see design as happening in the space between the societally desirable and the technically possible, the design situation itself at the micro level could include a potentiality for determinism. Philosophers of technology confirm that 
technological determinism may appear at the micro level, at least when various artefacts are used. Mitcham (1994) sketches the foundations of a phenomenology of artefacts, using examples from, for instance, Illich (1973), and claims that:

This initiating sketch of a phenomenology of artifacts begins to reveal a straightforward sense in which technology can become autonomous in relation to human users (if not makers), and it shows how different kinds of tools can have inherent features that ground distinctive impacts on societal orders. This is true independent of particular social contexts within which some particular tool might be embedded or the particular social processes it is associated with (Mitcham 1994, pp. 183-184).

One particularly illuminating and significant example of this is the way designed artefacts reflect and perpetuate gender relations, for example, blue toys for boys and black, angular razors for men, and pink toys for girls and red, smooth razors for women (Berner 2009; Wajcman 2010).

However, given Mitcham's line of reasoning, it should be clear that even the making of technological artefacts could be subjected to determinism. Following Vermaas et al. (2011), if the existing state of the art is successful, the desirable is less likely to be dominant, or more difficult to achieve, whereas a poor state of the art is likely to be succeeded by better designs (cf. Petroski 1992). However, evidence from a design education context suggests that it may not be so simple. For instance, Doboli and Umbarkar (2014) showed that design precedents in group discussions hampered design feature variety, solution novelty and quality when designing electronic embedded systems, but the precedents also helped improve the utility of the designs. Examples from architectural design, on the other hand, showed that for novice designers technological precedents could actually help externalize design knowledge from expert designers' repertoire and thus make it accessible; as such the precedents could boost creativity and novelty. Eilouti (2009) thus claims that:

The research has shown that the goal of the formulated precedent-based design models is not to create a deterministic representation of design solutions but rather to propose rudimentary components and prototypes that may help to initiate the designing process and to highlight new layers the incorporation of which may enrich the generated design products. As such, a design scheme is viewed as an assembly of many sub-systems and sub-solutions that are suggested by the PBKR models which offer basic vocabulary or templates for designers to follow and to develop into new alternatives (Eilouti 2009, p. 366).

Viswanathan and Linsey (2013) show that idea fixation (or, design fixation, see Jansson and Smith 1991) in design using physical models was not an inherent feature of model use, but was better explained by the Sunk Cost Effect; that is, that a person is reluctant to choose a different path of action due to prior investments in terms of money, time and/or effort. Consequently, their study confirms certain technological determinism in the form of idea fixation in design processes due to prior choices by the designers.

Prevailing evidence from design studies would thus seem to at least partly contradict Misa's notion of a macro level where technology is/seems deterministic, and a meso/micro level on which technology is/appears less deterministic (cf. also Mitcham 1994). There are, according to the above studies, technologically deterministic potentialities even at the micro level in design workshops and classrooms, even though, for instance, the Sunk Cost model (cf. path dependence) could be said to be softly deterministic, as idea fixation appears as a result of prior choices and (financial) investment in earlier ideas (Viswanathan 
and Linsey 2013). Although at the micro rather than macro level, this model is very similar to Hughes' (1987) concept of momentum, which has also been denoted as a soft determinist term.

Technological determinism may consequently not be something that is altogether "bad" in all situations, as was also noted above. Precedents, prior designs and technological structures may actually be used as mental role models and building blocks in new designs (e.g. Arthur 2009; Eilouti 2009), and in technological systems it may not even be possible to avoid deterministic tendencies (Vermaas et al. 2011). It is therefore a question of balance between the societal and technical factors that determine technological design (see Fig. 1), and the real issue here may be when technology really over-determines design (or, conversely, when society over-determines). An example of a possibly problematic deterministic potentiality is automated design that is carried out with artificial intelligence (AI), which has already been implemented in certain industrial branches (e.g. Carr 2015; Wiberg et al. 2019). Another example is digital, social media engagements that are algorithm driven, in the best interests of the social media companies. Especially when coupled with AI and machine learning, there is a deterministic potentiality in the sense that humans relinquish some degree of control of the technology.

\section{Concluding discussion: reconsidering technological determinism in technology education}

In this article I have investigated how philosophical, sociological and historical research, as well as design and innovation research about technological determinism, could be fruitfully reconsidered in technology education. There are, to begin with, three novel findings about the nature of technological determinism that the present analysis has yielded. First of all, technological determinism can take the form of an idea, theory or a way of explaining technology development in history or the present, but it can also take the form of actual material structures that-implicitly or explicitly-permeate and influence society, or, at least, this is what some researchers and scholars claim. However, these two forms of technological determinism are not always easy to distinguish. Furthermore, especially in historical research in which secondary sources most often have to be relied upon, it may be cumbersome if not impossible to study the determining effects of technology, although archaeology, hydraulic archaeology and "urban mining" are promising fields of research in this regard (cf. Buhagiar 2007; Wallsten et al. 2013).

Secondly, technological determinism is not just something that is the result of a bird's eye view of technology and society or when we study technology as part of the macro level of society (Misa 1994). Determinism can appear on all levels, even the micro level where technology is negotiated and developed in engineering offices or design workshops (Eilouti 2009; Mitcham 1994, pp. 181-191; Viswanathan and Linsey 2013). Thirdly, like its counterpart social/societal determinism, technological determinism is not necessarily a "bad" thing, but a natural result of technological design being a balance between what is societally desirable and what is technically possible. Edgerton (2011) points to the importance and ubiquitousness of old technological artefacts and structures in society, and Eilouti (2009) shows how in architectural design novice designers can actually become more creative when leaning on technological precedents. 
However, it may certainly be problematic if technology over-determines society and humans, particularly in certain contexts with critical deterministic potentialities. This is therefore also where there can be a clear connection to technology education, and technological literacy. Pannabecker (1991) critiques the metaphor of the "impact of technology" common in technology education discourse and curricula as potentially determinist, and suggests that:

The expression technological impacts needs to be abandoned as the primary metaphor for conceptualizing relationships between technology and society. These relationships are too complex to be understood solely as a set of causes and effects in which technology is the source of the causes and society the context of impacts. The immediate task is not, however, to find a single alternate metaphor but to recognize that there are different ways of approaching the study of technology and society. This diversity should be reflected in technology education programs, standards, and in the evaluation of programs (Pannabecker 1991, p. 8).

One reason to take Pannabecker's admonition to heart when addressing technological "impact" or over-determination on both the macro and micro level is the fact that many modern technological artefacts and systems are so complicated that no single person, or group of persons, has an overall grasp of them or knows the design in full, which means that the risk of unforeseen consequences of technology increases. For example, the 2019 grounding of the Boeing 737 MAX 8 after two consecutive fatal accidents in Indonesia and Ethiopia shows that airplanes are in themselves so complex to design, manufacture and operate that errors-human- or machine-related-somewhere in the system can result in catastrophic consequences (e.g. Arbesman 2017; Carr 2015; Hughes 2004).

On the micro level, technological determinism or over-determination can also take the form of design fixation, which is when designers adhere to a limited set of ideas or solutions in a design situation. Particularly in the school context, where novice designers are supposed to be educated, it is imperative to avoid fixation and promote both divergent and convergent thinking (cf. McLellan and Nicholl 2011; Schut et al. 2019; Stables 2014). Previous technological solutions, models or precedents can contribute to less design feature variety, solution novelty and quality (Doboli and Umbarkar 2014), and students performing fewer iterations between design stages (Botleng et al. 2019), although precedents may also enrich design and contribute to new alternatives (Eilouti 2009).

Today technology education and technological literacy are increasingly broadly defined, and design can therefore be construed as a process in which the students can put their own creative mark on technological artefacts and systems. McLain et al. (2019) claim that:

A unique feature of design and technology education is that technological artefacts not only mediate activity, but that learners engage with artefacts to design, make and evaluate their own artefacts - variously referred to as models, prototypes, systems or products - transforming the world around them [...] requiring that pupils defer judgement and manage ambiguity when designing (McLain et al. 2019, p. 14).

There is therefore another way in which technology can over-determine society and education that may be equally harmful: when humans think that they cannot control technology development or design processes. The idea of (hard) technological determinism, or over-determination, is thus in itself problematic, regardless of the actual existence of any deterministic technology in history or in the present, because what we think about technology will necessarily affect how we act in relation to it. And this matters from the point of view of technological literacy (Dakers 2006; Perdue 1994; Pleasants et al. 2019). 
Especially in these days of increased dependence on AI in various sectors of society, including schools, it is very important to emphasize that it is humans that design, and retain control over, technology. A central feature of technology education in schools is to educate the students so that they can question and critique the technologies that they choose to use and that shape their lives. Furthermore, students should be aware that in design processes all technologies will be the result of designerly acts and a multitude of choices made by engineers and designers, be it the design of stools, electronic circuits or autonomous systems.

Acknowledgements Open access funding provided by Linköping University.

Open Access This article is licensed under a Creative Commons Attribution 4.0 International License, which permits use, sharing, adaptation, distribution and reproduction in any medium or format, as long as you give appropriate credit to the original author(s) and the source, provide a link to the Creative Commons licence, and indicate if changes were made. The images or other third party material in this article are included in the article's Creative Commons licence, unless indicated otherwise in a credit line to the material. If material is not included in the article's Creative Commons licence and your intended use is not permitted by statutory regulation or exceeds the permitted use, you will need to obtain permission directly from the copyright holder. To view a copy of this licence, visit http://creativecommons.org/licenses/by/4.0/.

\section{References}

Ammon, S. (2017). Why designing is not experimenting: Design methods, epistemic praxis and strategies of knowledge acquisition in architecture. Philosophy \& Technology, 30, 495-520. https://doi.org/10.1007/ s13347-017-0256-4.

Ankiewicz, P. J. (2019). Andrew Feenberg: Implications of critical theory for technology education. In J. R. Dakers, J. Hallström, \& M. J. De Vries (Eds.), Reflections on technology for educational practitioners: philosophers of technology inspiring technology education (pp. 115-130). Boston, MA: Brill Publishers.

Arbesman, S. (2017). Overcomplicated: Technology at the limits of comprehension. New York: Portfolio.

Arthur, W. B. (2009). The nature of technology: What it is and how it evolves. New York: Free Press.

Axell, C. (2019). Langdon winner: A call for a critical philosophy of technology. In J. R. Dakers, J. Hallström, \& M. J. De Vries (Eds.), Reflections on technology for educational practitioners: Philosophers of technology inspiring technology education (pp. 131-146). Boston, MA: Brill Publishers.

Berner, B. (2009). Teknikens kön. In P. Gyberg \& J. Hallström (Eds.), Världens gång - teknikens utveckling. Om samspelet mellan teknik, människa och samhälle (pp. 279-293). Lund: Studentlitteratur.

Bijker, W. E. (1992). The social construction of fluorescent lighting, or how an artifact was invented in its diffusion stage. In W. E. Bijker \& J. Law (Eds.), Shaping technology/building society: studies in sociotechnical change (pp. 75-102). London \& Cambridge, MA: MIT Press.

Bijker, W. E. (1995). Of bicycles, bakelites, and bulbs: Toward a theory of sociotechnical change. Cambridge, MA and London: MIT Press.

Bimber, B. (1990). Karl Marx and the three faces of technological determinism. Social Studies of Science, 20(2), 333-351.

Bimber, B. (1994). Three faces of technological determinism. In M. R. Smith \& L. Marx (Eds.), Does technology drive history? The dilemma of technological determinism (pp. 79-100). Cambridge, MA: The MIT Press.

Botleng, V. J., Brunel, S., \& Girard, P. (2019). Learning through design and make: Producing originallythought-out products versus producing pre-designed products downloaded from data files. Paper presented at the PATT 37, Developing a knowledge economy through technology and engineering education, Msida, Malta.

Buhagiar, K. (2007). Water management strategies and the cave-dwelling phenomenon in late-medieval Malta. Medieval Archaeology, 51(1), 103-131.

Carr, N. (2015). The glass cage: How our computers are changing us. New York: Norton.

Dakers, J. R. (2006). Introduction: Defining technological literacy. In J. R. Dakers (Ed.), Defining technological literacy: Towards an epistemological framework (1st ed.). New York: Palgrave Macmillan. 
de Vries, M. J. (2009). Translating customer requirements into technical specifications. In A. Meijers (Ed.), Philosophy of technology and engineering sciences (pp. 489-512). Amsterdam: Elsevier.

de Vries, M. J. (2017). Philosophy as critique. In P. J. Williams \& K. Stables (Eds.), Critique in design and technology education (pp. 15-30). Singapore: Springer Nature.

Doboli, A., \& Umbarkar, A. (2014). The role of precedents in increasing creativity during iterative design of electronic embedded systems. Design Studies, 35, 298-326.

Dusek, V. (2006). Philosophy of technology: An introduction. Malden, MA: Blackwell.

Edgerton, D. (2011). Shock of the old: Technology and global history since 1900. London: Profile Books.

Eilouti, B. H. (2009). Design knowledge recycling using precedent-based analysis and synthesis models. Design Studies, 30, 340-368.

Ellul, J. (1962). The technological order. Technology and Culture, 3(4), 394-421.

Ellul, J. (1964). The technological society. New York: Vintage Books.

Feenberg, A. (1999). Questioning technology. London and New York: Routledge.

Feenberg, A. (2006). What is philosophy of technology? In J. R. Dakers (Ed.), Defining technological literacy: Towards an epistemological framework (pp. 5-16). New York: Palgrave MacMillan.

Feenberg, A. (2017). Technosystem: The social life of reason. Cambridge, MA and London: Harvard University Press.

Hallström, J. (2011). Urban or suburban water? working class suburbs, technological systems and environmental justice in swedish cities in the late nineteenth century. In G. Massard-Guilbaud \& R. Rodger (Eds.), Environmental and Social Justice in the City: Historical Perspectives. Cambridge: The White Horse Press.

Heilbroner, R. L. (1994). Technological determinism revisited. In M. R. Smith \& L. Marx (Eds.), Does technology drive history? The dilemma of technological determinism (pp. 67-78). Cambridge, MA: The MIT Press.

Högselius, P., Kaijser, A., \& van der Vleuten, E. (2016). Europe's infrastructure transition: Economy, war, nature. New York: Palgrave MacMillan.

Hughes, T. P. (1983). Networks of power: Electrification in Western Society, 1880-1930. Baltimore and London: Johns Hopkins University Press.

Hughes, T. P. (1987). The evolution of large technological systems. In W. E. Bijker, T. P. Hughes, \& T. J. Pinch (Eds.), The social construction of technological systems: New directions in the sociology and history of technology. London: The MIT Press.

Hughes, T. P. (2004). Human-built world: How to think about technology and culture. Chicago: University of Chicago Press.

Ihde, D. (1990). Technology and the lifeworld: From garden to earth. Bloomington and Indianapolis: Indiana University Press.

Ihde, D. (2006). The designer fallacy and technological imagination. In J. R. Dakers (Ed.), Defining technological literacy: Towards an epistemological framework (pp. 121-131). New York: Palgrave MacMillan.

Illich, I. (1973). Tools for conviviality. New York: Harper and Row.

Jansson, D. G., \& Smith, S. M. (1991). Design fixation. Design Studies, 12(1), 3-11.

Kaiserfeld, T. (2015). Beyond innovation: Technology, institution and change as categories for social analysis. Basingstoke: Palgrave MacMillan.

Kroes, P., Franssen, M., van de Poel, I., \& Ottens, M. (2006). Treating socio-technical systems as engineering systems: Some conceptual problems. Systems Research and Behavioral Science, 23, 803-814.

Latour, B. (1990). Technology is society made durable. The Sociological Review, 38(1), 103-131.

Latour, B. (1999). Pandora's hope: Essays on the reality of science studies. Cambridge, MA and London: Harvard University Press.

McClellan, J. E., III, \& Dorn, H. (1999). Science and technology in world history: An introduction. Baltimore and London: The Johns Hopkins University Press.

McLain, M., Irving-Bell, D., Wooff, D., \& Morrison-Love, D. (2019). How technology makes us human: Cultural historical roots for design and technology education. The Curriculum Journal. https://doi. org/10.1080/09585176.2019.1649163.

McLellan, R., \& Nicholl, B. (2011). "If I was going to design a chair, the last thing I would look at is a chair": Product analysis and the causes of fixation in students' design work 11-16 years. International Journal of Technology and Design Education, 21(1), 71-92.

Melosi, M. V. (2000). The sanitary city: Urban infrastructure in America from colonial times to the present. Baltimore: The Johns Hopkins University Press.

Misa, T. J. (1994). Retrieving sociotechnical change from technological determinism. In M. R. Smith \& L. Marx (Eds.), Does technology drive history? The dilemma of technological determinism (pp. 115142). Cambridge, MA: The MIT Press. 
Mitcham, C. (1994). Thinking through technology: The path between engineering and philosophy. Chicago: The University of Chicago Press.

Nee, V., \& Cao, Y. (1999). Path dependent societal transformation: Stratification in hybrid mixed economies. Theory and Society, 28(6), 799-834.

Nightingale, P. (2009). Tacit knowledge and engineering design. In A. Meijers (Ed.), Philosophy of technology and engineering sciences (pp. 351-374). Amsterdam: Elsevier.

Pannabecker, J. R. (1991). Technological impacts and determinism in technology education: Alternate metaphors from social constructivism. Journal of Technology Education, 3(1), 1-11.

Perdue, P. C. (1994). Technological determinism in agrarian societies. In M. R. Smith \& L. Marx (Eds.), Does technology drive history? The dilemma of technological determinism (pp. 169-200). Cambridge, MA: The MIT Press.

Petroski, H. (1992). The evolution of useful things: How everyday artifacts-From forks and pins to paperclips and zippers-Came to be as they are. New York: Alfred A. Knopf.

Pitt, J. C. (2006). Human beings as technological artifacts. In J. R. Dakers (Ed.), Defining technological literacy: Towards an epistemological framework (pp. 133-142). New York: Palgrave MacMillan.

Pitt, J. C. (2014). "Guns don't kill, people kill”; values in and/or around technologies. In P. Kroes \& P.-P. Veerbek (Eds.), The moral status of technical artefacts (pp. 89-101). Dordrecht: Springer.

Pleasants, J., Clough, M. P., Olson, J. K., \& Miller, G. (2019). Fundamental issues regarding the nature of technology. Science \& Education, 28, 561-597.

Schot, J., \& Scranton, P. (2016). Making Europe: An introduction to the series. In P. Högselius, A. Kaijser, \& E. Van der Vleuten (Eds.), Europe's infrastructure transition: Economy, war, nature (pp. 9-12). New York: Palgrave MacMillan.

Schut, A., Klapwijk, R., Gielen, M., \& De Vries, M. J. (2019). Children's responses to divergent and convergent design feedback. Design and Technology Education: An International Journal, 24(2), 67-89.

Scranton, P. (1994). Determinism and indeterminacy in the history of technology. In M. R. Smith \& L. Marx (Eds.), Does technology drive history? The dilemma of technological determinism (pp. 143-168). Cambridge, MA: The MIT Press.

Shapin, S. (1992). Discipline and bounding: The history and sociology of science as seen through the externalism-internalism debate. History of Science, 30, 333-369.

Squatriti, P. (1998). Water and society in Early Medieval Italy, AD 400-1000. Cambridge: Cambridge University Press.

Stables, K. (2014). Designerly well-being: Implications for pedagogy that develops design capability. Design and Technology Education: An International Journal, 19(1), 9-20.

Staudenmaier, J. M. (1985). Technology's storytellers: Reweaving the human fabric. Cambridge, MA: Society for the History of Technology and the MIT Press.

Updike, J. (1995). Introduction. In J. Updike (Ed.), Rabbit Angstrom: A tetralogy. New York, London and Toronto: Alfred A. Knopf, Everyman's Library.

Vermaas, P., Kroes, P., van de Poel, I., Franssen, M., \& Houkes, W. (2011). A Philosophy of technology: From technical artefacts to sociotechnical systems. San Rafael, CA: Morgan \& Claypool Publishers.

Viswanathan, V. K., \& Linsey, J. S. (2013). Role of sunk cost in engineering idea generation: An experimental investigation. Journal of Mechanical Design, 135, 1-12.

Wajcman, J. (2010). Feminist theories of technology. Cambridge Journal of Economics, 34, 143-152.

Wallsten, B., Carlsson, A., Frändegård, P., Krook, J., \& Svanström, S. (2013). To prospect an urban mineAssessing the metal recovery potential of infrastructure "cold spots" in Norrköping, Sweden. Journal of Cleaner Production, 55, 103-111.

Wiberg, A., Persson, J., \& Ölvander, J. (2019). Design for additive manufacturing-A review of available design methods and software. Rapid Prototyping Journal. https://doi.org/10.1108/RPJ-10-2018-0262.

Williams, R. (1994). The political and feminist dimensions of technological determinism. In M. R. Smith \& L. Marx (Eds.), Does technology drive history? The dilemma of technological determinism (pp. 217235). Cambridge, MA: The MIT Press.

Winner, L. (1977). Autonomous technology: Technics-out-of-control as a theme in political thought. Cambridge, MA: MIT Press.

Winner, L. (1986). The whale and the reactor: A search for limits in an age of high technology. Chicago and London: The University of Chicago Press.

Publisher's Note Springer Nature remains neutral with regard to jurisdictional claims in published maps and institutional affiliations. 